\title{
Blaschko Linear Enamel Defects - A Marker for Focal Dermal Hypoplasia: Case Report of Focal Dermal Hypoplasia
}

\author{
Stefan Gysin ${ }^{a} \quad$ Peter Itin ${ }^{b, c}$ \\ ${ }^{a}$ Faculty of Medicine, University of Basel, and Departments of ${ }^{b}$ Dermatology and \\ 'Biomedicine, University Hospital Basel, Basel, Switzerland
}

\section{Key Words}

Focal dermal hypoplasia - Goltz-Gorlin syndrome - Blaschko lines - Enamel defects · PORCN gene

\begin{abstract}
Focal dermal hypoplasia (FDH) is a rare genetic skin disorder. The inheritance of FDH or Goltz-Gorlin syndrome is X-linked dominant and the disease is associated with a PORCN gene mutation. This gene plays a key role in the Wnt pathway, which has an impact on embryonic development. Every tissue derived from meso- and ectoderm can be affected. Patients suffer from cutaneous, ocular, osseous, oral and dental defects. The skin and dental alterations manifest along the Blaschko lines. We present a woman (born in 1962) suffering from FDH with congenital skin changes and Blaschko linear enamel defects. Typical symptoms (e.g. fat herniations, scoliosis, syndactyly, microphthalmia, caries and alopecia) plus vertical grooving of all teeth gave a first indication. Molecular genetic testing confirmed the definitive diagnosis of FDH. We hypothesize that, in the context of typical skin changes, visible Blaschko lines on the teeth in the form of vertical grooves are almost pathognomonic for $\mathrm{FDH}$.

(c) 2015 S. Karger AG, Basel
\end{abstract}

\section{Introduction}

We report a woman with focal dermal hypoplasia (FDH) and Blaschko linear enamel defects. FDH or Goltz-Gorlin respectively Goltz syndrome is a rare genetic skin disorder within

KARGER 125/s $\quad \begin{aligned} & \text { Stefan Gysin } \\ & \text { University Hospital Basel } \\ & \text { Petersgraben 4 } \\ & \text { CH-4031 Basel (Switzerland) } \\ & \text { E-Mail stefan.gysin @ stud.unibas.ch }\end{aligned}$


Gysin and Itin: Blaschko Linear Enamel Defects - A Marker for Focal Dermal Hypoplasia: Case Report of Focal Dermal Hypoplasia

the large spectrum of ectodermal dysplasias [1]. The disease is associated with a PORCN gene mutation. Its protein plays a key role in the Wnt pathway, which has an impact on embryonic development. The inheritance is X-linked dominant, therefore $90 \%$ of affected people are female. Hemizygous men are not viable [2]. Apart from the skin, common manifestations appear on the teeth, eyes, skeleton and face. Theoretically every tissue of meso- and ectoderm origin can be altered. Intelligence is mostly unaffected [3].

\section{Case Description}

We present a woman (born in 1962) suffering from FDH. The patient has had congenital skin changes and scoliosis since birth.

A first dermatological examination at the age of 19 years showed pigmentary changes, atrophic skin areas and telangiectasias. Hypopigmentation appeared as focal, pea-like, white spots on the thorax, back, forearms, knees, front thighs and secondary inguinal. Hyperpigmentation occurred as brown, irregular skin alterations following the lines of Blaschko. Furthermore syndactyly (toes II/III) and fat herniations with piezogenic papules were found. The dental changes included malposition of the lower incisors and vertical grooving of all teeth (fig. 1). In context with all the other symptoms and manifestations, these alterations gave a first indication for the diagnosis of FDH.

At the age of 48 years a second consultation took place. In addition to the abovementioned symptoms and findings, more typical features of the disease were detected. The patient showed microphthalmia on her right eye. She wears contact lenses due to myopia and astigmatism. The case history also revealed that she has been suffering from reflux since the age of 20. Since then, annual ablation of esophageal papillomas was conducted. The clinical examination unveiled fragile teeth with caries. Poikiloderma (skin areas of hypo- and hyperpigmentation, telangiectasis and atrophy), particularly on the legs, was confirmed (fig. 2). The patient suffered from circumscribed hair loss (alopecia). Like her mother, she showed dystrophic nails. Beside the scoliosis, a shortening of her left leg was found. The scoliosis led to painful humpback. Slight nail clubbing was observed. The patient suffered from periocular scars (status after several laser therapies) and perioral papules with hypertrichosis.

The patient has already had five abortions and has one son with astigmatism, myopia and hyperopia. Her mother had several abortions too and also showed conspicuous symptoms: slight depigmentation on the legs, lipomas, brittle hair and teeth variations.

Molecular genetic testing confirmed the diagnosis of FDH. A mutation in the PORCN gene was found, potentially in condition of mosaicism. The accurate position is c.1284+1 in intron 14.

The further procedure includes frequent dermatological examinations (due to painful skin lesions), search for the mutation (identified in the patient) in the mother and physiotherapy to strengthen the musculoskeletal system.

\section{Discussion}

Our patient shows typical signs of FDH. Beside the atrophic skin areas and fat herniations, hypo- and hyperpigmentation along the Blaschko lines were found. The orthopedic ailments consist of syndactyly and scoliosis with its consequences (e.g. pain). Moreover, eyes abnormalities and recurring esophageal papillomas disturb the patient's wellbeing. The clin- 
Gysin and Itin: Blaschko Linear Enamel Defects - A Marker for Focal Dermal Hypoplasia: Case Report of Focal Dermal Hypoplasia

ical features are generally more pronounced on her left side, an interesting observation already described in other cases. The presumable cause is selective X inactivation [2].

In our case the dental changes include malposition, fragile teeth, enamel hypoplasia with caries and generalized vertical enamel grooving, all distinctive signs for Goltz syndrome [4]. The vertical ridges of the teeth run along the Blaschko lines. Those lines represent epidermal cell migration and proliferation of embryonal development. Normally invisible, they only become manifest in a few skin diseases [3]. We hypothesize that, in the context of typical skin changes, visible Blaschko lines on the teeth in the form of vertical grooves are almost pathognomonic for FDH. Still, for a definite diagnosis, a detailed clinical investigation of the whole patient and a genetically proven mutation is required in any case. A possible differential diagnosis of dental analogies of Blaschko lines with enamel impairment is X-linked amelogenesis imperfecta, though those patients normally do not show any other symptoms than caries, abnormal color and temperature hypersensitivity of the teeth [5].

The diagnosis in our patient was confirmed by genetic testing. The patient has a mutation in the PORCN gene. Unfortunately her mother did not agree to genetic counseling and analysis, thus we do not know for sure whether it is a familial or a sporadic case of FDH. However, this case provides evidence for an inherited, familial case. Mother and daughter had several abortions and both show dystrophic nails. Furthermore the mother suffers from depigmentation of the skin, multiple lipomas, brittle hair and dental changes, without a doubt characteristic symptoms for FDH. However, without the genetic proof of mutation the disease cannot be verified $100 \%$. Our patient's son cannot have inherited the mutation from his mother due to the fact that heterozygous male embryos are not viable. Males survive only in mosaic form or as Klinefelter syndrome [6]. The described eye changes are consequently independent from FDH. He does not show any other symptoms of the disease.

On suspicion of familial cases of Goltz syndrome, genetic counseling and analysis is highly recommended. Once the disease-causing gene in a family is identified, prenatal molecular genetic testing can be conducted in expectation of pregnancy. Mothers with FDH show a higher rate of miscarriages and stillbirths [3].

\section{Conclusion}

Striated lines on the teeth in combination with skin changes and further meso-/ectodermal alterations point to the diagnosis of Goltz syndrome (FDH). Especially the dental ridges, representing Blaschko lines, are almost pathognomonic. However, not all patients present them. If suspicious features on the skin are found, the teeth should be examined and vice versa. In any case cooperation between dermatologists, dentists and other specialists is required for the diagnosis and treatment of FDH.

In familial cases genetic counseling is highly recommended, so that the exact location of the PORCN gene mutation can be identified. If patients desire to have children, the identified mutation simplifies prenatal molecular genetic testing.

\section{Statement of Ethics}

The authors confirm the informed consent of the patient. The research complies with all ethical guidelines for human studies and animal welfare regulations. 


\section{Case Reports in Dermatology}

\begin{tabular}{l|l}
\hline DOI: $10.1159 / 000430781$ & $\begin{array}{l}\text { (c) 2015 S. Karger AG, Basel } \\
\text { www.karger.com/cde }\end{array}$ \\
\hline
\end{tabular}

Gysin and Itin: Blaschko Linear Enamel Defects - A Marker for Focal Dermal Hypoplasia: Case Report of Focal Dermal Hypoplasia

\section{Disclosure Statement}

There are no sponsorship or funding arrangements related to this paper. Therefore, no conflicts of interests exist.

\section{References}

1 Goltz RW, Henderson RR, Hitch JM, Ott JE: Focal dermal hypoplasia syndrome. A review of the literature and report of two cases. Arch Dermatol 1970;101:1-11.

-2 Wang X, Reid Sutton V, Omar Peraza-Llanes J, Yu Z, Rosetta R, Kou YC, Eble TN, Patel A, Thaller C, Fang P, Van den Veyver IB: Mutations in X-linked PORCN, a putative regulator of Wnt signaling, cause focal dermal hypoplasia. Nat Genet 2007;39:836-838.

-3 Hall EH, Terezhalmy GT: Focal dermal hypoplasia syndrome. Case report and literature review. J Am Acad Dermatol 1983;9:443-451.

-4 Balmer R, Cameron AC, Adès L, Aldred MJ: Enamel defects and lyonization in focal dermal hypoplasia. Oral Surg Oral Med Oral Pathol Oral Radiol Endod 2004;98:686-691.

5 Lagerström M, Dahl N, Nakahori Y, Nakagome Y, Bäckman B, Landegren U, Pettersson U: A deletion in the amelogenin gene (AMG) causes X-linked amelogenesis imperfecta (AIH1). Genomics 1991;10:971-975.

-6 Alkindi S, Battin M, Aftimos S, Purvis D: Focal dermal hypoplasia due to a novel mutation in a boy with Klinefelter syndrome. Pediatr Dermatol 2013;30:476-479.

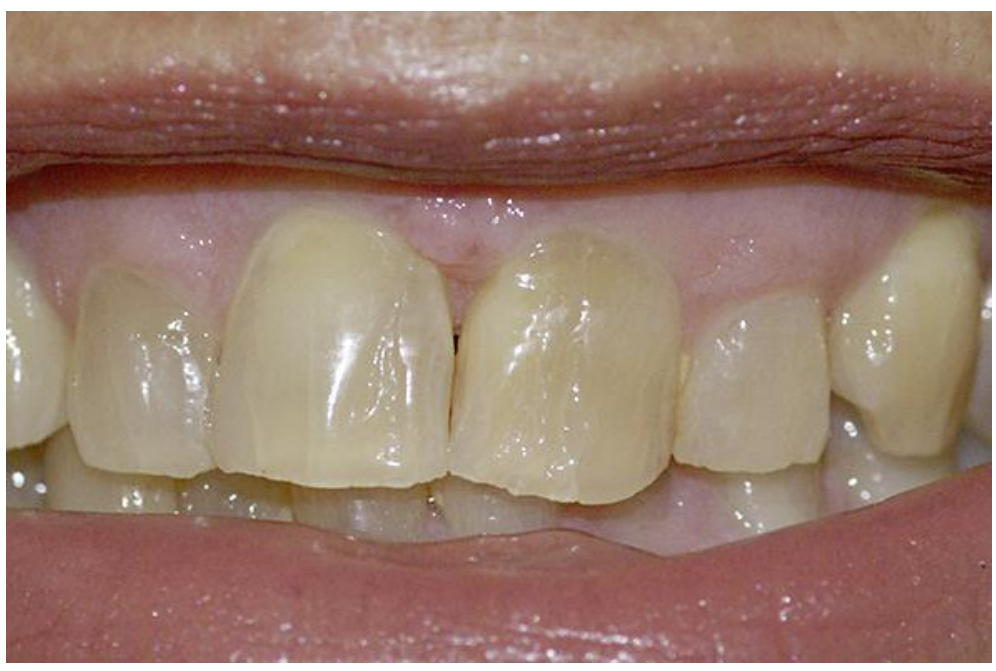

Fig. 1. Vertical grooving of the upper front teeth. 
Case Reports in
Dermatology

Case Rep Dermatol 2015;7:90-94

DOI: $10.1159 / 000430781$

(C) 2015 S. Karger AG, Basel

www.karger.com/cde

Gysin and Itin: Blaschko Linear Enamel Defects - A Marker for Focal Dermal

Hypoplasia: Case Report of Focal Dermal Hypoplasia

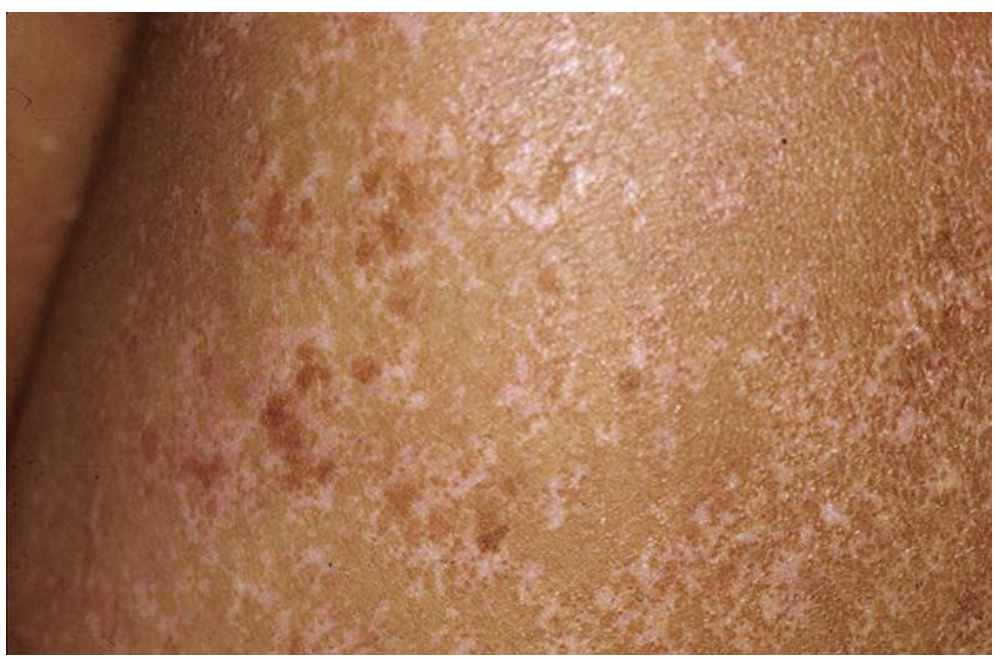

Fig. 2. Poikiloderma (leg). 